\title{
Influência do porta-enxêrto no número de sementes da laranja
}

\author{
HEITOR W. S. MONTENEGRO
}

E. S. A. Luiz de Queiroz

SYLVIO MOREIRA, Instituto Agronômico, Campinas

ร. PIMENTEL GOMES,

E. S. A. Luiz de Queiroz

\section{BENJAMIN CINTRA,}

Secretaria da Agricultura do Estado de S. Paulo 


\section{1 - INTRODUÇÃO}

E bastante conhecida, em fruticultura, a influência do "cavalo" sôbre o enxêrto. Nos citros, em particular, recebeu êsse assunto especial atenção de numerosos pesquisadores, estando hoje perfeitamente comprovada a marcante ação dos vários porta-enxertos sôbre o "cavaleiro". Assim, foram constatados serem influenciados o tamanho, a forma, o vigor, a época de florescimento e de frutificação, a precocidade de produção, a susceptibilidade a doenças e a resistência a geadas da planta cítrica; do fruto sofrem a ação do porta-enxêrto o tamanho, espessura, rugosidade e coloração da casca, quantidade de suco, teôr em ácidos, açúcares e vitamina C.

As razões determinantes das modificações dessas características, que a princípio foram supostas ser apenas devidas a melhor ou pior compatibilidade anatômica entre enxêrto e cavalo, sabe-se, hoje, serem muito mais complexas e de difícil explicação.

O presente estudo foi realizado visando-se esclarecer a influência do cavalo sôbre o número de sementes em algumas variedades de laranja. Consultando-se a vasta bibliografia sôbre citrus, principalmente a ótima revisão sôbre o assunto apresentada por WEBBER (1948), pôde-se observar que essa influência ainda não tinha sido mencionada.

\section{2 - MATERIAL E MEtODO}

As plantas que forneceram os frutos para êste estudo fazem parte de três experimentos de porta-enxertos instalados em 1957 na Estação Experimental do Instituto Agronômico, em Tietê.

Frutos de três variedades de Citrus sinensis Osbeck, da safra de 1958, foram examinados: laranjas Baianinha, Hamlin e Maracanã. A lar. Baianinha está enxertada em 10 portaenxertos; a lar. Hamlin sôbre 8 e a lar. Maracanã sôbre 6 porta-enxertos.

O delineamento desses experimentos é de blocos ao acaso, com 4 repetições e 3 plantas por parcela $(4 \times 3=12$ plantas de cada combinação).

Amostras de dez frutos foram retiradas de cada árvore (30 de cada repetição e 120 de cada cavalo). 
As sementes foram extraidas dos frutos pelo método de expressão a mão e para efeito de contagem consideraram-se apenas as perfeitamente desenvolvidas.

\section{3 - RESULTADOS}

\section{Laranja Baianinha}

1.1. - Número médio de sementes por fruto

\begin{tabular}{|c|c|c|}
\hline & Porta-enxêrto & Número de sementes \\
\hline $\begin{array}{l}\text { a) } \\
\text { b) } \\
\text { c) } \\
\text { d) } \\
\text { e) } \\
\text { f) } \\
\text { g) } \\
\text { h) } \\
\text { i) } \\
\text { j) }\end{array}$ & 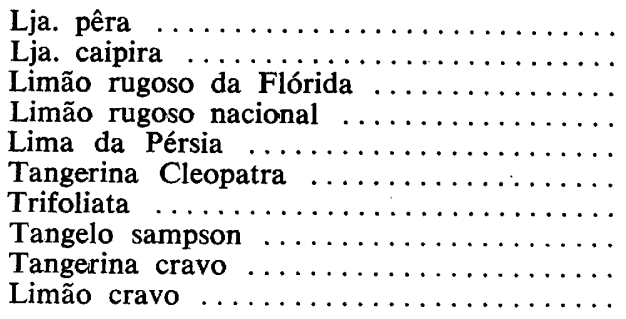 & $\begin{array}{l}0,07 \text { sementes } \\
0,08 \text { sementes } \\
0,04 \text { sementes } \\
0,05 \text { sementes } \\
0,25 \text { sementes } \\
0,23 \text { sementes } \\
0,17 \text { sementes } \\
0,64 \text { sementes } \\
0,07 \text { sementes } \\
0,05 \text { sementes }\end{array}$ \\
\hline
\end{tabular}

1.2. - Análise da variância

\begin{tabular}{|c|c|c|c|}
\hline Causa da variação & G. L. & S. Q. & Q. M. \\
\hline Repetições .... & 3 & 6,09 & 2,03 \\
\hline Tratamentos & 9 & 12,48 & $2,03++$ \\
\hline Resíduo & 27 & 11,45 & 0,42 \\
\hline
\end{tabular}

1.3. - Por esta análise da variância observa-se que os tratamentos mostraram diferença significativa ao nível de $1 \%$ de probabilidade, donde se conclui que os diversos cavalos usados para a laranja Baianinha, influiram diferentemente, com relação ao número de sementes existentes nos frutos.

Pela comparação entre as médias de tratamentos e fazendo-se uso do teste de Tukey a $5 \%$ de probabilidade, observa-se 
que o porta-enxêrto tângelo sampson mostrou diferença significativa em relação com o aumento do número de sementes. As diferenças apresentadas pelos demais porta-enxertos não são significativas.

2. Laranja Maracanã

2.1. - Número médio de sementes por fruto

\begin{tabular}{|c|c|c|}
\hline ! & Porta-enxêrto & Número de sementes \\
\hline a) & Lja. pêra & 18,17 sementes \\
\hline & Limão rugoso da Flórida & 6,91 sementes \\
\hline & Lima da Pérsia & 5,69 sementes \\
\hline & Limão cravo & 4,72 sementes \\
\hline e) & Lja. caipira & 4,64 sementes \\
\hline f) & Trifoliata & 3,45 sementes \\
\hline
\end{tabular}

2.2. - Análise da variancia

\begin{tabular}{|c|c|c|c|}
\hline Causa da variação & G. L. & S. Q. & Q. M. \\
\hline Repetições & 3 & 16,88 & 5,63 \\
\hline Tratamentos & 5 & 140,05 & $28,01++$ \\
\hline Resíduo & 15 & 69,26 & 4,62 \\
\hline
\end{tabular}

Pela presente análise da variância constata-se que os tratamentos mostraram diferença significativa ao nivel de $1 \%$ de probabilidade.

Pelo uso do teste de Tukey a $5 \%$ de probabilidade na comparação entre as médias de tratamentos, verifica-se que o porta-enxêrto laranja pêra mostrou diferença significativa ao nivel de $5 \%$ no aumento do número de sementes nos frutos de laranja Maracanã, enquanto que os demais porta-enxertos não mostraram diferenças significativas entre sí. 


\section{Laranja Hamlin}

3.1. - Número médio de sementes por fruto

\begin{tabular}{|c|c|c|}
\hline & Porta-enxêrto & Número de sementes \\
\hline & Lja. pêra & 5,6 sementes \\
\hline b) & Trifoliata ... & 5,2 sementes \\
\hline c) & Tangerina cravo & 5,5 sementes \\
\hline d) & Limão rugoso nacional & 5,1 sementes \\
\hline e) & Lima da Pérsia & 5,1 sementes \\
\hline f) & Lja. caipira .... & 5,0 sementes \\
\hline g) & Limão rugoso da Flórida & 4,8 sementes \\
\hline h) & Limão cravo .... & 5,1 sementes \\
\hline
\end{tabular}

3.2. - Análise da variância

\begin{tabular}{|c|c|c|c|}
\hline Causa da variação & G. L. & S. Q. & Q. M. \\
\hline Repetições & 3 & 0,51 & 0,17 \\
\hline Tratamentos & 7 & 0,87 & 0,12 \\
\hline Resíduo & $\begin{array}{l}21 \\
.\end{array}$ & 1,92 & 0,09 \\
\hline
\end{tabular}

A análise da variância mostra-nos não haver diferença significativa entre os tratamentos, donde se conclui que as variedades de porta-enxertos usados apresentaram efeito idêntico em relação ao número de sementes existentes nos frutos da variedade Hamlin.

Contagem de sementes em frutos da safra de 1959, confirmaram os resultados acima apresentados para tôdas as combinações mencionadas. 


\section{4 - DISCUSSÃO DOS RESULTADOS}

Como se constata pelos resultados do presente estudo, os porta-enxertos possuem a capacidade, até hoje não mencionada, de influir sôbre o número de sementes da variedade enxêrto. Essa descoberta é de grande importância pois está em contradição com a afirmativa generalizada de que o número de sementes é uma característica normal da variedade. MOREIRA \& GURGEL (1941) assim o dizem: "O número de sementes por fruto é um caráter importantíssimo da variedade. Desconhecem-se quais os fatores fisiológicos ou mesológicos que o afetam".

Embora se procurasse uma possível influência de fatores externos, tais como variação do tipo de solo, visinhanças de outras variedades, etc. a nenhưm dêles pôde ser atribuida a ação em questão.

E de se ressaltar que as gemas que deram origem às mudas foram retiradas de uma única planta, em cada variedade.

Depreende-se desses resultados que a influência no aumento do número de sementes, não é causada apenas pelo "cavalo" e sim da interação entre "cavalo" e "cavaleiro". Daí a razão porque se verificou um aumento de sementes nas combinações Baianinha/tângelo-sampson e Maracanã/lja. pêra e nenhuma ação nas laranja Baianinha/laranja-pêra e laranja Hamlin/lja.-pêra o que deveria ser esperado se a influência fôsse devida apenas ao porta-enxêrto.

Essa hipótese da interação explicaria os resultados obtidos por BRIEGER \& GURGEL (1941) no seu estudo sôbre a influência do cavalo sôbre a fertilidade do polem. Em suas conclusões dizem êles: "os cavalos podem ter efeito sôbre a fertilidade do polem do cavaleiro, seja produzindo aumento ou redução, estatisticamente significantes em alguns casos, e sem nenhum efeito noutros. Esse efeito, porém, não parece sistemático; uma espécie de cavalo em combinação com diferentes cavaleiros pode dar diferentes resultados".

A ação portanto deve ter como causa a interação do conjunto cavalo-enxêrto, não sendo devida ao efeito do cavalo sòmente.

Levando-se em conta de que MOREIRA \& GURGEL (1941), em observações feitas em numerosas espécies cítricas, encontrararam uma correlação positiva entre fertilidade do polem e número de sementes, pode-se explicar a razão do au- 
mento do número de sementes, naquelas combinações, por um correspondente aumento na fertilidade do polem.

Apesar de considerarmos mais favorável essa hipótese, não é de se desprezar a possibilidade de uma ação também sôbre o pistilo, melhorando a auto-compatibilidade.

\section{5 - CONCLUSÓES}

1) Constatou-se uma influência de certas combinações cavalo-enxêrto no número de sementes da variedade-enxêrto. A variedade Baianinha quando enxertada sôbre tangelo Sampson e a variedade Maracanã quando sôbre laranja pêra mostraram possuir maior número de sementes do que quando enxertadas sôbre outros "cavalos".

2) As razões que determinaram o aumento do número de sementes podem ser explicadas por um aumento da fertilidade do polem, devido a uma ação fisiológica provocada pelo conjunto cavalo-enxêrto.

\section{6 - BIBLIOGRAFIA CITADA}

BRIEGER, F. G. \& J. T. A. GURGEL, 1941 - Influência do cavalo sôbre a fertilidade do polem no cavaleiro, em Citrus. Bragantia 1 $(11,12)$ : 713-757.

MOREIRA, SILVIO \& J. T. A. GURGEL, 1941 - A fertilidade do polem e sua correlação com o número de sementes, em espécies e formas do gênero citrus. Bragantia $1(11,12)$ : 669-711.

WEBBER, H. J., 1948 - Rootstocks: their character and reactions. Em Batchelor, L. D. \& H. J. Webber. ed. The Citrus Industry. University of California Press. Vol. 2. p. 69-168. 
